went to an Institute where, under an injection of some local anaesthetic, large pieces of skin were removed from both the upper and lower eyelids. Collodion dressings were applied, and the patient sent home. She suffered intense pain and swelling of the eyelids and conjunctiva, and, according to her own account, one of them became septic. We have also heard of a case in which the palpebral aperture had been enlarged by an external canthotomy performed for "small eyes." Apparently there is nothing in the British law which prevents such operations being performed by unqualified practitioners, unless a fatality occurs. This was instanced some years ago when some unqualified Indian oculists were brought before the courts for removing portions of the eyelids and conjunctiva, and were acquitted.

It would be of service if ophthalmic surgeons would collect similar cases so that some representation could be made with regard to this unqualified practice which seems to be on the increase.

\title{
Transactions of the Ophthalmological Society
}

Special interest attaches to the Transactions of the Ophthalmological Society of the United Kingdom, Vol. XXXVI, recently issued to members, for not only does it contain an account of the 1918 Congress of the Society but also of the meetings of two of the four affiliated societies, namely, the Oxford Ophthalmological Congress and the Midland Ophthalmological Society. Among the contributions of the affiliated societies the Doyne Memorial Lecture on "Ophthalmology and the War," by Sir William Collins, should be mentioned. It recalls vividly the memory of one whose name is dear to many of us, the late Robert Walter Doyne, founder of the Oxford Congress, and of much besides. For instance, to him is owing the foundation of the Oxford Eye Hospital and the inception of a diploma of ophthalmology in the University of Oxford. These were but the preliminary steps towards a more ambitious dream which he never lived to see fulfilled, which was the rendering of Oxford a centre of ophthalmology for the British Isles. Sir William Collins in speaking of him quotes the fine saying of Ralph Waldo Emerson, "An institution is the lengthened shadow of one man," and never was that truer than in the case of our colleague. The affiliation movement, carried out largely by the then President of the Ophthalmological Society, has our warmest approval, more especially at a time such as this when union is truly strength. Under this scheme the autonomy of the individual society is not affected, but an account of its work will appear in the Transactions. This is an advantage to those societies which have not in the past published a separate volume, as well as to those who belong exclusively to the 
parent society, who will now enjoy the privilege of reading for themselves an account of the scientific work carried on by the other bodies.

\section{The National Physical Laboratory}

It is but fitting that in a technical journal such as this notice should be paid to the important work on optics that is done by the National Physical Laboratory at Teddington, of which the report for the year 1917-18 is before us. Since the outbreak of war, heavy demands upon the Optics Division of the Laboratory have been made by the testing of instruments, such as gun-sights and lookout telescopes and binoculars, and sextants, and material such as optical glass. The number of specimens of glass examined for refractive purposes has risen largely above last year's total. The tests are made on a Pulfrich refractometer, and experience shows that a properly constructed instrument of that type used under suitable conditions gives results only attainable by most other methods with the expenditure of much more time and trouble. There have been several requests for the examination for optical properties of specimens of glass not specially prepared for the purpose, and in such cases the tests were carried out by an immersion method. The method has proved adequate to enable the particular glass to be identified, although the accuracy has been less than that which is secured when suitably prepared specimens are tested. The Division has done a considerable amount of work dealing with optical calculations, chiefly concerned with economizing the time involved in calculations, either by extracting more complete information from rays traced through a system or by substituting a definite algebraic system of operations for tentative ray tracing in cases where the algebraic method has proved to be applicable as a final method of calculation. The algebraic methods aim at replacing the years of experience required in the other system by a definite course of operations which will, within the field of their applicability, lead to a satisfactory solution of the problem. A considerable part of the additional buildings now under construction at Teddington will provide accommodation for the testing of glass volumetric apparatus, most of which was formerly obtained from Germany. As it is now made in this country, the Committee of the Research Department dealing with the matter is anxious that the standardization of such glassware should be undertaken by the Laboratory.

\section{Nerve Fibres of the Living Cornea}

In the Lancet for November 23, 1918, will be found a short abstract of an article by J. Strebel, of Lucerne, Correspondenzbl. fiir 